\title{
La agonía de la ética y la antropología Notas a partir del pensamiento de Manuel Marzal
}

\section{Luis Mujica Bermúdez}

\author{
Recuerdo dos normas. \\ Una es no engañar a los informantes, \\ aunque no hay que decirles toda la verdad... \\ Otra norma de la ética es no herir \\ la sensibilidad de los investigados.
}

Tierra encantada

RESUMEN

El artículo consta de tres partes. En la primera parte considera las anotaciones de Manuel Marzal, antropólogo y profesor de Pontificia Universidad Católica del Perú, fallecido en el año 2005, sobre el tema de la ética como preocupación temática desde la antropología. En segundo lugar, se hace una revisión - a modo de balance bibliográfico-sobre el mismo tema contrastando las preocupaciones de Marzal con la producción de los últimos años, sobre todo en el área peruana, realizada por diversos antropólogos quienes han abordado de forma explícita o implícita el tema ético o moral. Finalmente, en un contexto de postviolencia política y del Informe Final de la Comisión de la Verdad y Reconciliación, se propone que para hacer una antropología de la ética en estos tiempos debe considerarse dos referencias metodológicas y cuatro dimensiones para explorar la conducta de las personas en relación con otras. Las referencias metodológicas requieren de una «densa descripción» de las moralidades para tratar de entender la simplicidad de las relaciones e investigar y reflexionar el tema en una perspectiva multidisciplinar. 
Las cuatro dimensiones en las cuales se debe indagar la ética son la vida cotidiana, la religiosidad, la economía y política.

Palabras clave: ética, moralidad, agonía, política, economía, vida cotidiana, Marzal

This paper is divided into three different sections. The first section considers the annotations of Manuel Marzal, an anthropologist and professor at the Pontificia Universidad Católica del Perú who passed away in the year 2005, about ethics as a concern coming form an anthropological perspective. Secondly, the article presents a balance on the bibliography about this issue, contrasting Marzal's preoccupations with the latest bibliography, mainly Peruvian, which deals with ethics and morals in an explicit or implicit sort of way. Finally, living in the post-political violence and Commission for Truth and Reconciliation Final Report period, in order to make an anthropology on ethics one has to consider two methodological references and four dimensions to explore the people's behaviors in relation to others. The methodological references require a «dense description» on morality to try to understand the simplicity of the relations and investigate and reflect on a multidisciplinary perspective. The four dimensions in which to explore ethics are daily life, religiosity, economics and politics.

Key words: Ethics, morality, agony, politics, economics, daily life, Marzal 
Durante los últimos años de su vida, Manuel Marzal reiteraba su preocupación porque no veía estudios sobre la ética desde la perspectiva antropológica. Debo decir a Marzal que su persistente pregunta había sido escuchada por muchos de sus discípulos. Para otros humanistas y científicos sociales era un tema también de preocupación y buscaban aportar luces para vivir mejor como seres humanos. En esta ocasión, con las manecillas del reloj detenidas, a) recojo y resumo las anotaciones de Marzal sobre el tema de la ética, b) del mismo modo entrego un ramillete de ideas de antropólogos que han abordado el tema en los últimos años de forma explícita o implícita sobre el tema moral o ético, y c) apuro algunos comentarios finales a modo de reflexión sobre la agonía de la ética en el Perú de hoy «durante Ayacucho» (Gutiérrez 1986: 223). Esta última expresión quiere subrayar, sobre todo, el sentido que tiene el tiempo para las víctimas de la violencia política en el Perú; pues el sufrimiento en ellas continúa aún presente y, en cambio, para otros, o pertenece al pasado, o nunca existió.

\section{EL LEGADO DE MANUEL MARZAL}

La preocupación de Marzal ${ }^{1}$ sobre el tema de la ética se remonta a sus primeras investigaciones antropológicas. En 1977, en sus «Estudios sobre religión campesina», identifica una «dimensión moralista» que se refleja en la obligación de guardar ciertas reglas. Sin embargo, no quedaba claro — dice Marzal - «hasta qué punto puede hablarse de una dimensión ética», menos aún si el campesino

\footnotetext{
En adelante, citaré «Estudios sobre religión campesina» $=(\mathrm{ERC}) ;$ «La transformación religiosa peruana $»=(\mathrm{TRP}) ;$ «El sincretismo iberoamericano» $=(\mathrm{SI}) ;$ «Los caminos religiosos de los inmigrantes en la gran Lima $»=(\mathrm{CRI}) ; \mathrm{y}$ «Tierra encantada» $=(\mathrm{TE})$.
} 
ha logrado descubrir «la caridad al prójimo como un verdadero culto espiritual» (ERC: 290). La perspectiva antropológica estaba directamente relacionada con la pastoral cristiana, que era también su perspectiva de vida personal y vocacional.

En el año 1983 retoma la cuestión ética en «La transformación religiosa peruana». La ubica como uno de los aspectos de su investigación y critica la perspectiva evolucionista que en cierta medida negaba la dimensión ética de las religiones primitivas. Sin embargo, para centrar el tema y señalar la importancia del mismo dice que la

ética andina estaba orientada, por una parte, a asegurar las relaciones equitativas dentro del grupo, resumidas en la repetida fórmula 'no robes, no mientas y no estés ocioso' en una sociedad basada en la 'reciprocidad' y, por otra parte, a asegurar la veneración hacia los seres del mundo sagrado, que premiaban o castigaban la conducta de los humanos sobre todo con sanciones intramundanas. Las raíces éticas cristianas se basaban en el decálogo revelado por Dios a Moisés y redefinido por Jesucristo en el sermón del monte y en todo su mensaje evangélico, pero se expresaban en el comportamiento concreto de los españoles de fines de la edad media, que marca una verdadera decadencia moral (TRP: 33 ).

Por ello, para entender la ética en su dimensión diacrónica, se requería de todas maneras llevar a cabo «alguna periodización» en la cual se debe considerar la «percepción de la moral cristiana por el indio» en el proceso peruano, pero también la percepción de las etapas en las que ha habido «una catequización más seria y un sistema ritual y organizativas florecientes» (TRP: 433-434) que han generado personas con «valores cristianos».

La enseñanza de la ética colonial, sin embargo, dice Marzal, pasó por tres modalidades: la denuncia de Las Casas, la utopía de minimizar las relaciones coloniales y la prédica que prescindía del sistema. La primera tendencia inspiró una corriente a manera de una «escuela de denuncia» que elevaban muchos clérigos y laicos y que planteaban la licitud o conveniencia de las encomiendas, el servicio personal y el repartimiento mercantil (TRP: 434). La segunda tendencia era aquella de los misioneros que querían cumplir con su misión mediante la evangelización en espacios especiales para los indios, como eran las doctrinas o las reducciones y que tuvo momentos de gloria. La tercera tendencia mayoritaria era aquella evangelización que se hizo sin cuestionar el sistema colonial de fondo (TRP: 434-436) ${ }^{2}$

2 Castro en Moral moderna, moral de pícaros ¿NO ES El Perú, un proyecto moderno: una aproximación al pensamiento peruano?, dice que «la moral del conquistador es una moral moderna, que se justifica a sí misma y justifica la conquista; que legisla sobre el bien y el mal teniendo como punto de partida no una racionalidad metafísica o religiosa, sino el interés y la ambición del moderno sobrepuesto al mundo colectivo y social» (1994: 192). 
y que de algún modo se impuso durante mucho tiempo. Sin embargo, Marzal era muy consciente que el problema ético en esas tendencias quedaba pendiente y su desarrollo dependía de la relación con la matriz andina y cómo desde esta cultura se fue haciendo una lectura de la ética colonizadora y se ejerció realmente.

Dos años mas tarde, Marzal publica El sincretismo Iberoamericano (1985), en el cual sistemáticamente considera la ética como una dimensión del estudio de la religión en Cusco, Chiapas y Bahía. En el mundo andino, oponiéndose nuevamente a los evolucionistas, afirma que existe una ética en la medida en que dichas «normas comprenden tanto ciertos preceptos universales impresos en el corazón del hombre como la aplicación de los mismos» (SI: 37). Del mismo modo, en el mundo tzotzil y tzeltal, los indios tienen «arraigado un concepto de pecado que puede acarrear desgracias en el mundo presente sin que se destaquen sus repercusiones en la vida del más allá, cuyo código ético concluye tanto las prohibiciones universales de las ética humana (no matar, no robar, no cometer adulterio, etcétera) como otras prohibiciones que se refieren al mandamiento del mundo cultural de las respectivas comunidades» (SI: 74). Finalmente, en el candomblé, donde hay autonomía como grupo, las personas están regidas por una serie de tabúes, deberes culturales y de solidaridad con los miembros de su propio grupo, pero - insiste Marzal reiteradas veces-, «como en la del sistema andino y maya, es el aspecto sobre el que se dispone de menos información, por haber sido mucho menos investigado y por tratarse de religiones más centradas en el culto que en la moral» (SI: 100).

Una vez dicho esto, Marzal intenta una interpretación general diciendo que los grupos han «reinterpretado» las prácticas manteniendo su postura teórica del sincretismo mediante el cual, por ejemplo, el mundo andino y maya ha convertido el compadrazgo en uno de los lazos más importantes de solidaridad social (SI: 190). Sin embargo, Marzal, comprometido con su rol pastoral, al final del libro, y desde una perspectiva de la inculturación dice: «juzgo que tanto indios como negros han desarrollado formas de ayuda mutua, como maneras de organizar el intercambio en su sociedad o como mecanismo de defensa ante la prolongada explotación o marginación de que han sido objeto por las respectivas sociedades nacionales, que deben ser asumidas como fundamento de su ética social» (SI: 223). Este último punto es sumamente importante en tanto que la ética no debía ser considerada solo un mero objeto «positivista» de estudio del comportamiento humano, sino debía ir más allá, es decir, ver el significado de las implicancias de las relaciones entre unos y otros.

La producción de Marzal no se detiene. En Los caminos religiosos de los inmigrantes en la gran Lima (1988) establece una tipología sobre las iglesias en el distrito de El Agustino, Lima, en el cual propone, del mismo modo, que cada tipo de iglesia tendría su manera de asumir la ética. En primer lugar, los inmigrantes 
en Lima se insertan en el marco de una perspectiva secular en la que el campesino experimenta cambios en su vida que afecta diversas dimensiones. Sobre este punto Marzal señala que

el campesino rompe con una naturaleza sacralizada, especialmente en el mundo surandino, donde siguen vigentes los ritos agrarios a la Pachamama y a los Apus o Wamanis, y con una concepción sacral de la enfermedad; rompe, además, con una cultura sacralizada por las relaciones de reciprocidad, que se consideran sagradas, y por la fiesta del santo patrono, que es la expresión religiosa-comunitaria más importante. Pero, rompe también con una sociedad campesina, cuyo catolicismo popular no es tan vivo como a veces se supone, sino que está sometido a una verdadera involución, debida a la escasa presencia institucional que ha tenido la Iglesia desde hace bastantes décadas (CRI: 196).

La llegada de los migrantes a los barrios marginales es un encuentro con la informalidad; con el horizonte secularizante de un saber científico y técnico, con un mundo desarticulado y duro. Pero también se encuentra con una red de santuarios tradicionales y una iglesia católica diferente, con una espiritualidad bíblica y un compromiso con la promoción y organización popular. Por esta razones, Marzal piensa que la llegada a la ciudad no «seculariza» a los inmigrantes necesariamente, porque encuentran los provincianos formas de reconstrucción de sus «fiestas patronales».

Del mismo modo, considera que la «iglesia popular» se caracteriza fundamentalmente por la reflexión bíblica y el compromiso fraterno de sus miembros, sin dejar de lado la devoción a los santos. Esta manera de entender la religiosidad está acompañada, por ejemplo, por cambios en las percepciones de un «Dios del aquí y del ahora» a un «Dios de la vida», pero con ciertas dudas porque «el Dios de la vida parece opacarse ante el sufrimiento», pero está cercano (CRI:239). Sin embargo, también se percibe que existe «el más allá» y que al mismo tiempo, y de manera paradójica, hay una sanción intramundana.

Estas ideas se refuerzan con una espiritualidad en la que se destaca la «opción por los pobres» que han tomado sus miembros y la necesidad de actuar para superar la pobreza en diversos campos. En efecto, se menciona sobre esta espiritualidad que tiene, implícitamente, una ética allí donde la fe en los santos se va convirtiendo en tanto se participa de la reflexión bíblica y se motiva al compromiso social, orientados con un Dios de la vida, en un Cristo bíblico y en una iglesia que ha optado por los pobres. Aunque en este texto no aparece de manera explicita el tema ético, Marzal trata de resolver un problema central: «la devoción a los 'santos' convive con la nueva espiritualidad de las CC (comunidades cristianas)» y no sabe «si esta convivencia es una síntesis creativa hecha por el pueblo creyente o es solo 
un momento de transición hacia una espiritualidad. En la que los 'santos' se vayan definitivamente o, al menos, pierdan la gran importancia que siguen teniendo» (CRI: 263). Marzal, por supuesto, se inclina por la primera alternativa. Cree en una población que reinterpreta creativamente su vida de fe.

En la tercera parte de su trabajo sobre Los caminos religiosos, presenta a las «nuevas iglesias» y las clasifica como evangélica, pentecostal y escatológica. En el estudio de estos grupos aparece visiblemente en el índice del libro: «organización y ética». En estos puntos señala, para todos los casos, que la Biblia es una norma fundamental en la vida de dichos grupos y se explicita en las abstenciones que deben hacer los creyentes de determinadas comidas, bebidas y adornos. Pero también señala el pacifismo y la preocupación por la problemática social y, en otros casos, la ascética de la huida del mundo, la poligamia y el desarrollo económico (Cf. CRI: 280, 292, 316, 328, 342). Marzal compara a los diversos grupos desde dos variables importantes: la ética convencional y la política. En la primera considera las relaciones interpersonales y en la segunda las relaciones con la colectividad.

Finalmente, en 2002, Marzal publica Tierra Encantada. Este es su libro final y total; allí — como él mismo lo decía en nuestras conversaciones- condensa su pensamiento y preocupación por la cuestión religiosa en oposición de quienes pensaban que la religión ya había muerto y sucumbido con la modernidad. En esta magistral obra, la cuestión ética sigue apareciendo como preocupación pero no como objeto de estudio. Como se trata de un libro síntesis de sus trabajos, él define la ética como «un conjunto de normas, cuyo cumplimiento es exigido por las creencias que se tienen, y así muchas religiones dan valor religioso a las normas de la ética natural, como no matar, o imponen nuevas normas, como no tomar bebidas alcohólicas» (TE: 28).

Como Marzal mismo concluye, el único lugar donde tomó el tema de ética propiamente como tema de estudio ha sido en el capítulo VII de Tierra encantada y la hace en relación con la política, aspecto que no podía eludir de sus reflexiones como sacerdote jesuita. Marzal nuevamente trata de definir la ética como el «conjunto de valores que funcionan como sistema normativo de los comportamientos individuales y colectivos» (TE: 173); además, considera como sinónimos ética y moral, aunque menciona que la primera establece diferencias entre lo bueno y lo malo, y la segunda tiene más bien un carácter normativo e imperativo para el individuo. La preocupación de Marzal por tener una definición exhaustiva era una de sus tareas primordiales y que quería concluir para seguir avanzando en investigaciones posteriores.

Ya que para Marzal el tema de la ética era un punto que no podía dejar de pensar, él se hace dos preguntas generales, las cuales trata de responder y esbozar en dos líneas de trabajo: ¿son éticas las religiones primitivas? y ¿son funcionales y 
eficaces las éticas seculares? (TE: 173). La primera sigue siendo una pregunta para desterrar definitivamente el prejuicio evolucionista e intolerante de tendencias que tratan de establecer «grados» de cultura en la que la religión podría ser descartada simplemente. En cambio, la segunda pregunta oculta su preocupación por si la ética debe seguir apoyándose en la perspectiva religiosa, cuando en el escenario social se habla incluso de ética laicas, como lo hacen muchos autores.

En el debate, Marzal estudia la relación entre ética y religión, y ética y política. A propósito de la primera relación, por una parte, vuelve a discutir con una corriente evolucionista británica (Tylor) para mostrar que otro británico como Evans-Pritchard, con su estudio sobre La religión nuer, muestra la complejidad de la religión y define el pecado como la «infracción de una prohibición que trae consigo la imposición de sanciones de índole espiritual» (TE: 174). Por otra parte, basándose en El crepúsculo del deber, de Lipovetsky, distingue la ética religiosa, la secular y la posmoralista. El interés de este despliegue bibliográfico es el mostrar que la cuestión religiosa se mantiene vigente y que atañe a la vida de la sociedad contemporánea y, siguiendo a Küng, sostiene que la religión en la actualidad puede ayudar al hombre y también mantener la cohesión de la sociedad. En síntesis, no es la ética la que ayuda a sostener la vida, sino la religión y esta tiene, en todos los tiempos, una ética que merece la pena ser estudiada porque cumple el rol de dar sentido a la vida, es garantía y finalmente es seguridad y es una resistencia contra las injusticias.

En la segunda parte, Marzal establece la relación entre religión y política y en esta parte discute con Weber luego de hacer una escueta reseña. Por un lado, presenta el espíritu del capitalismo y el ethos puritano calvinista. Después menciona las tipologías religiosas, mística y ascética, y combina estas variables con las metas intramundanas o extramundanas en cada caso. El confucianismo es, por ejemplo, una religión mística e intramundana; el hinduismo es mística y extramundana. En cambio, el judaísmo es una religión mística e intramundana y el catolicismo una religión ascética y extramundana. Una vez establecida esta tipología, Marzal hace el «juicio sobre la tesis de Weber», recogiendo las crítica de Samuelson y Morris de quienes recoge la idea de que «no hay prueba empírica para la correlación espíritu del capitalismo-ética protestante, y que la descripción de Weber de la ética puritana traiciona a sus fuentes» (TE: 193).

Después de su Tierra encantada, Marzal no escribió sino pequeños artículos, presentaciones de libros y en Para entender la religión en el Perú 2003 (2004) realiza «Algunas preguntas pendientes sobre la religión en América Latina», donde presenta preguntas y observaciones a propósito del tema de la religión; y mantuvo una de las preguntas que siempre quiso responder: 
¿Por qué la ética sigue siendo olvidada en los estudios de antropología de la religión, aunque se acepte que todas las religiones son éticas, aunque en distinto grado? ¿Por qué los antropólogos — la mayoría de ellos hijos de la Ilustración y testigos de cómo en sus propias sociedades la dimensión vertical hacia Dios ha perdido vigencia frente a la dimensión horizontal hacia el hombre- no han estudiado la dimensión ética en la modernización del mundo tradicional? ¿Por qué los antropólogos no han analizado más la aceptación de las éticas puritanas, el surgimiento de los fundamentalismos éticos, la sacralidad subyacente en la ética secular y la eficacia real de la ética posmoralista para la convivencia humana? (TE: 43).

Así como sus preguntas dejan un camino por allanar, sus observaciones son como pequeñas señales que debemos considerar antes de pasar a la siguiente parte. Sugiere hacer, en primer lugar, «etnografías» sobre la dimensión ética (individual y colectiva) en las «sociedades tradicionales»; en segundo lugar, analizar el concepto de pecado a partir de los requisitos fijados por la sociedad y el por qué de la sanción intramundana de un Dios que premia y castiga en la vida presente; $y$, finalmente, señala los métodos que posiblemente sean los más pertinentes para dicho estudio sabiendo que es «difícil saber dónde se sitúa la persona y si comunica lo que piensa realmente o lo que parece pensar en una determinado contexto»y claro - una vez más - Marzal concluye al decir que «en la investigación de la experiencia subjetiva y de la ética de la religión hay, como decía César Vallejo, muchísimo que hacer» (TE: 45).

\section{EL RAMILLETE DE NOTAS SOBRE MORALIDADES Y ÉTICAS}

Las preocupaciones por la ética y la moral en las ciencias sociales no son recientes. Probablemente fue Malinowski quien desarrolló en el capítulo XIII, «La vida sexual de los salvajes», publicado en inglés en 1929 (1971), acerca de la moral y las costumbres de los trobriandeses. El autor en mención dice que «la 'inmoralidad', en el sentido de ausencia de todo freno, regla o valor, no existe en ninguna civilización, por pervertida y desprovista de base que sea». Se trata de un punto importante para establecer una relatividad cultural de la moralidad. Más recientemente, Howell (1997) publicó The Ethnography of Moralities con un número importante de artículos sobre las moralidades en diversos lugares del planeta. Sin embargo, nuestro interés aquí es más bien distinto.

Muchos de los que conocieron a Marzal mantuvieron — en el subconsciente — la idea de desarrollar algún día el tema de la ética y seguramente aquella intuición maduró en algunos y permitió tocar el tema de alguna manera. Sin embargo, el tema de la ética supera la cuestión de las relaciones de amistad y docencia. 
Probablemente otros autores lo han abordado de muchas maneras, pues la manera de relacionarse cotidianamente entre seres humanos es sumamente importante para dejar de hacerlo. La ética, definitivamente, es un tema trasversal y toca las diversas dimensiones de la vida, la economía, la política, la educación, la vida cotidiana y la religiosidad. Aquí solo recojo algunos de aquellos trabajos - considerando la cronología de su publicación y con la seguridad de no poder incluir a muchos otros - a modo de ofrenda tardía para Manuel Marzal en forma de un ramillete de ideas sobre las maneras de entender la ética.

Quizás uno de los primeros antropólogos que comienza a considerar el tema de la ética sea José Luis González, en el diagnóstico que se hace sobre La religión popular en el Perú (1987). El capítulo VIII de este libro desarrolla la dimensión ética de las personas en el campo de la religiosidad popular y que Marzal hace alusión en Los caminos religiosos... (p. 256). En dicho estudio se analiza las «obras» del cristiano, los pecados y cómo entender las condiciones sociales. Las conclusiones van en la siguiente dirección: la fuerza de la ética o del juicio de valor se deriva de los derechos elementales del hombre: vida, trabajo, etcétera; que la ética popular obtiene sus criterios de vida de las exigencias de la realización humana; que el juicio ético popular se encuentra en la relación «Dios-hombre-norma ética-relaciones sociales» (González 1987: 159), vale decir que la relación del hombre con Dios es el fundamento de la dignidad y el respeto que la persona se merece. Sin embargo, en el campo de las relaciones interpersonales (matrimonio, sexualidad) los criterios éticos que se generan en el campo popular son diferentes a las inculcadas por la moral tradicional. Por ejemplo, se valora la «convivencia» sin que signifique un pecado, pero también hay conciencia de que el matrimonio sigue siendo una forma de realización de la persona y el divorcio es jugado como nocivo por la mayoría de los entrevistados.

Adams y Valdivia (1991), al estudiar el comportamiento de los migrantes micro empresarios, señalan que buscaban entender - lo que nosotros podríamos decir «ética» de manera implícita - las «motivaciones, valores y actitudes que orientan las prácticas sociales y económicas del mundo de la informalidad» (1991: 14) y encuentran que la cultura andina influye en la racionalidad empresarial popular porque la herencia cultural andina se sostiene en valores de laboriosidad, austeridad y capacidad de planificación. En el capitulo tres, bajo el título «Experiencia campesina e iniciativa empresarial», los autores esbozan los rasgos de una ética que tiene como meta el «progreso». La importancia de esta ética es la «actitud positiva de cambio» que creen ver en los migrantes empresarios, pues «el anhelo de progreso condiciona una actitud de búsqueda y sirve a la vez como soporte para el desarrollo de un itinerario lleno de incertidumbres, riesgos y fracasos, que le dan a ese halo de 'aventura' que se percibe al escuchar sus propios testimonios» (1991: 41). 
El estudio revela, sobre todo, los aspectos positivos de los microempresarios aunque también perciben que hay «olvido y ruptura». También existe una «prolongación y recreación» de una parte de los valores, costumbres y pautas de comportamientos en los migrantes a los que denominan «activo cultural». Este activo cultural consiste en la valoración del «trabajo, el manejo cuidadoso de los escasos recursos económicos, habilidades para planificar en condiciones muy adversas y el cumplimiento de deberes comunales» (1991: 44). Los microempresarios logran salir adelante cuando despliegan la idea de ser «independientes» y la «ética del trabajo», la que se manifiesta en las aspiraciones personales, la dedicación al negocio y el uso del escaso tiempo (cf. 191: 52). A estos aspectos, los autores añaden la concepción rígida del deber, el sentido de la laboriosidad, la honradez y la disciplina, así como un relativo sentido del ahorro y de austeridad.

Como es obvio, estas notas sobrevaloran el comportamiento de los microempresarios sin hacer una crítica, aunque esto no significa necesariamente que la ética del micro empresario no tenga también factores desconocidos y que forman parte de su ethos social y conductual. En esta misma línea apunta Soto (1998), quien prefiere denominar «la ética del progreso» e incidir además en la modificación de las identidades culturales de los pobladores porque «existe una gran cantidad de personas que buscan de una y otra manera un progreso en su vida» (pág. 20). El autor presume que la laboriosidad, la reciprocidad y la autonomía son valores que forman parte de los microempresarios cuyas actitudes observa.

En la zona ecuatoriana, Chávez (cf. Ehrenriech 1991) analiza a su manera la ética empresarial y el comportamiento político entre los Otavalo. Los tejedores comerciales tienen valores y creencias en su vida expresadas en la racionalidad, la honestidad y la sobriedad y en la auto percepción de sí mismos como innovadores, ansiosos de independencia económica y el de trabajar para ellos mismos (1991: 200). La racionalidad y la honestidad se manifiestan en la «responsabilidad» que equivale a realizar cuidadosamente sus actividades cotidianas. La honestidad consiste en actuar con justicia y con responsabilidad con aquellos con quienes interactúan continuamente y «les gusta describirse como los iniciadores de un nuevo estilo de tejido, diseño o artículo» (cf. 1991: 205). Sin embargo, estos aspectos, logrados en el campo económico, se desvirtúan en el campo político, pues «la meta política de obtener el poder despierta duda de su honestidad. El político no puede ser innovador y a la vez mantener el status quo. El político debe mantener y depender de las redes de individuos poderosos y, por lo tanto, ya no es capaz de acciones independientes y propias» (1991: 218). Al parecer, según Chávez, las relaciones en el campo económico forman mejor una «ética» que en el campo político, el cual, más bien, es el espacio de la suspicacia y de la desconfianza. Punto importante que se debe considerar para estudios posteriores. 
Un trabajo etnográfico es una fuente inagotable para examinar todas las dimensiones de la vida de la gente. Escalante y Valderrama (1992), en Nosotros los humanos, se encargan de presentar la vida de algunos campesinos de la zona de Cotabambas, Apurímac. El testimonio de «Ñuqanchik runakuna» muestra descarnadamente el ethos, la moral o la ética, de algunos cotabambinos. Una moral consuetudinaria que no se entiende sino en tanto el ser humano se entiende a sí mismo, vinculado intrínsecamente con la naturaleza, con sus creencias y con sus conocidos. No existe la «maldad», el robo es solo un eterno retorno de la venganza que hace que la reciprocidad explique las relaciones en una rueda sin fin. El sistema patriarcal se refuerza y no hay manera de evitarlo. El único obstáculo para la vida «ética» en el mundo de los cotabambinos es el «otro» en forma de policía, juez o agente externo que encarcela sin ninguna explicación a los inocentes y deja libres a los abigeos y asesinos. «Si te vamos a pagar, es nuestra falta», dijeron los tres. Así, recién fueron libres. Pero ellos hasta hoy día no han pagado. Se silenció el robo. Se perdió siempre nuestra papa» (p. 83), dice uno de los testimonios. En otro lugar, alguien sentencia: «Cuando yo muera, este ladrón les va a quitar; es envidioso y flojo. Todo su ganado lo está terminando. Él es flojo, su mujer también es floja. Separando pastarían aparte. Pero sí es bueno para vender el ganado a ocultas» (p. 56).

Se podría seguir citando muchos textos, pero Escalante y Valderrama, en la introducción del libro, mencionan que el abigeato en Cotabambas es «especial», pues «el robo de ganado está ligado al ayni, a la reciprocidad, al sentido de hacer justicia, de castigar a los tacaños, a los delatores y de hacer respetar los derechos» (p. $\mathrm{XX}$ ). Estas apreciaciones nos llevan por caminos que aún no han sido explorados, como diría Marzal, y que es necesario seguir estudiando y tratando de entender si la reciprocidad es como la «ley», que explica todas las relaciones más allá del bien y del mal, si cabe citar a Nietzsche. ¿Cuál es el sentido de la justicia en el mundo andino y si la búsqueda de la retribución escapa o no al deseo de la venganza, punto de partida para que la violencia siga operando en las mentalidades sociales? Sin duda, el texto de Escalante y Valderrama es un mar revuelto que merece ser hurgado con agudeza y ciencia, así como elaborar una propuesta de una «ética andina», tal como Estermann trata de hacer, comparando el pensamiento andino con el pensamiento occidental.

A los estudios en el campo religioso y en el campo económico y político se integra un estudio importante. Santos Granero (1994) emprende uno de los trabajos más completos de lo que podemos denominar como una etnografía de la ética y la política. Se propone desarrollar «las concepciones filosóficas e ideológicas de los Amuesha en torno a la realidad del poder, el conocimiento y la moralidad» (p. 19) bajo una óptica teórica en la que, de modo simple y claro, dice: «Mi interés radica en las múltiples conexiones (armónica y antagónicas) que existen entre el mito y 
la conducta social y, sobre todo, en la forma en la cual los mitos proponen (o no) directrices para la acción social» (p. 18). Estos puntos nos bastan para sostener que Santos - quizás sin proponérselo- nos da los elementos suficientes para una excelente «etnografía» de las moralidades, en tanto estudia las formas de conflictos y las armonías existentes entre los Amuesha. Aunque parezca paradójico, el amor y la armonía parecieran entrar en concordancia con las diversas violencias en el seno del grupo.

Sin embargo, es en «El uso moral de conocimiento y del poder» (capítulo V), donde Santos hace un relato importante sobre los patrones que estarían rigiendo el ethos entre los Amuesha. La reciprocidad es el principio que rige la generosidad entre las partes y, por lo tanto, la codicia y la mezquindad son actitudes «inmorales, irracionales y antisociales que conducen a la muerte o a la pérdida de la inmortalidad» (1994: 313). En este mundo, las autoridades cumplen roles definidos y sin ambigüedades. Entonces, su rol político se desempeña con claridad y genera una «comunidad moral», a tal punto que «la expresión máxima del poder místico es el acto de dar la vida, razón por la cual dicho poder está dotado del más alto valor moral» (p. 359). Sin embargo, el ejercicio del poder no es monocorde ni diáfano: está atravesado por la ambivalencia que proviene del carácter mismo del que detenta el poder. Así, el poder es ambivalente (shamanes, curanderos y hechiceros) y puede ser leído por la distancia que existen entre los grupos y el grado de cohesión de dichos grupos.

En 1995, en medio de un clima de cambios en el mundo contemporáneo, aparece Tierra Baldía, un ensayo de Fernando Fuenzalida, libro sobre el que Marzal quiso escribir una reseña y no sé si logró hacerlo (o quizás sus comentarios en los pasillos se quedaron en el tintero o traspapelados en la ruma de esbozos de algún artículo). En el ensayo mencionado, Fuenzalida dice que "para quienes fuimos educados en un modo distinto del sentir y el pensar, este mundo de ahora aparece como irracional, incongruente, inmoral y arbitrario. Despiadado en una medida y sentido que exceden las peores pesadillas de ayer. Babilonia, lo llamaba un colega. Para otro, a quienes el vértigo arrastra y que han olvidado que hubo una vez, illo tempore, un modo más racional, más estable y amable de vivir esta vida, todo ello aparece normal» (pp. 10-11). Estas reflexiones colocan al «antropólogo social» en la postura de observador y participante escéptico dispuesto a «creer siempre en todo y a confiar siempre en nada. Y, por supuesto, también viceversa» (p. 12). Se trata, por lo tanto, de un ensayo sobre la ética política en el mundo contemporáneo, pues se hace la «paciente observación de conductas ajenas y de mis propias conductas y estados internos [...] de la naturaleza impermanente e ilusoria del laberinto de relatividades que llamamos sociedad y cultura» (p. 12).

Al final de su trabajo, Fuenzalida concluye con dos «consejos» a los agentes pastorales y políticos. Por un lado, recomienda el camino del «ecumenismo 
tolerante, flexible y sensato, tratando de comprender que (los asuntos contemporáneos) no se trata de un problema de autoridad pastoral que pueda ser resuelto por el 'brazo secular' con medidas de disciplina o de fuerza» (p. 188). Por otro lado, a los agentes políticos o de ley, «conviene reconocer que sus instituciones operan en un medio cada vez más plural en el que la diversidad de costumbres y hasta de usos morales se hace un hecho corriente. Mientras la secularidad del principio legal no haya sido totalmente abolida, la violación de las leyes seguirá siendo delito punible, pero no la 'inmoralidad' en el fuero privado» (p. 189). Dos programas ético-políticos que habría que tener en cuenta en investigaciones sobre la cuestión ética en el mundo postmoderno.

Mujica (1998), en una encuesta a los estudiantes que ingresaban a la Universidad Católica en 1997, asumiendo la posibilidad de la coexistencia de valores tradicionales, modernos y postmodernos, concluye que entre los encuestados se encontraban jóvenes en condiciones familiares y económicas relativamente buenas, los que se percibían como satisfechos de la vida y relativamente felices con lo que tienen; por otro lado, los jóvenes se sentían relativamente libres y valoraban su autonomía, consideraban la igualdad como un valor, así como también la responsabilidad. La participación se daba, sobre todo, en la búsqueda de espacios de realización y pensaban que la solidaridad era un valor que no se podía abandonar fácilmente. En la segunda parte del trabajo, concluye que «los valores que permiten afirmar la modernidad entre los jóvenes son la responsabilidad, la puntualidad y la honestidad; paradójicamente, los valores considerados menos importantes son la belleza, la buena presencia y la virginidad o castidad que podría corresponder a la postmodernidad» (p. 76).

Estermann, filósofo suizo, luego de vivir en el Cusco durante muchos años, publica Filosofía andina (1998). Se trata de un estudio intercultural de la sabiduría andina, inusual en su especie y al mismo tiempo uno de los aportes más importantes para comprender la «mentalidad andina». Probablemente se trata de un libro original e interdisciplinar y, por ello, sujeto a muchas lecturas y observaciones. Sin embargo, para el tema que nos toca ahora, resulta una manera de sistematizar sobre la «ruwanasofía: ética andina». Estermann concluye que la ética andina no se restringe al ser humano ni al radio de la libertad individual. Antes bien, en la ética andina hay un fundamento axiológico basado en el orden cósmico, en la «relacionalidad universal de todo lo que existe» (p. 228) y, en este sentido, la ética es fundamentalmente recíproca: es una «ética del cosmos» en la medida en que «cada acto y comportamiento tiene consecuencias cósmicas». Por ello es una ética también «religiosa y teologal» (p. 229).

En esta misma dirección, aparece el libro pionero de Peña (1998), abogado y antropólogo, sobre antropología jurídica, que desarrolla el sentido de la justicia 
comunal en Calahuyo. En él, señala que los principios quechuas: ama sua (no robar), ama llulla (no mentir) y el ama q'ella (no ser ocioso) son los que rigen la vida de los individuos en el grupo, constituyen la base del honor en la vida comunal y condicionan un tipo ideal de hombre y mujer comuneros. Este honor juega un rol muy importante en la resolución de los conflictos de la comunidad. La imagen del hombre comunero honorable está identificada con el trabajo, con los negocios y la participación en los asuntos públicos; lo contrario a este ideal es el hombre altanero, ocioso y borracho. La imagen de la mujer comunera honorable se caracteriza por ser fiel compañera, que cumple con las actividades domésticas y sustituye los roles de la pareja en determinadas circunstancias (pp. 55-59).

La honorabilidad es un patrón ético que debe regir en el campo privado y en el público. El honor en el campo familiar se traduce en la confiabilidad, a tal punto que «honor y confianza se llegan a identificar en las actividades diarias de los comuneros» (p. 234). En el mundo colectivo se sabe que el interés familiar está subordinado al interés comunal: «la familia de más honor es aquella que justamente tiene más anhelo por el progreso de la comunidad» (p. 238) y, por supuesto, la armonía comunal resultaba ser un sinónimo de desarrollo comunal.

Muñoz y Rodríguez (1999), desde lo que es ahora la Universidad Antonio Ruiz de Montoya, vuelven al tema de la ética presente entre los microempresarios con una pregunta importante: «¿cómo ser buena persona en ausencia de una buena sociedad?» (p. 29). La intención de las autoras es la de indagar qué piensan, hacen y anhelan los que trabajan en la industria y el comercio en medio de condiciones muchas veces difíciles y contradictorias. Las entrevistas son leídas desde la perspectiva del testimoniante. En ellas se descubre la conciencia que tienen del trabajo y el valor que le dan, tanto porque es un espacio de realización como de responsabilidad con los otros; es de este modo que los sujetos buscan el reconocimiento necesario para afirmar su existencia como personas. De ahí que la pregunta final que se hacen las autoras muestran nuevamente la importancia de las maneras de relacionarse con los otros: ¿cómo imaginar una comunidad en donde los sujetos sientan que pertenecen plenamente a ella y estén dispuestos a cooperar con otros, si estamos construyendo una sociedad atravesada por tanta ausencia de reconocimiento debido? (p. 119).

A inicios del siglo XXI, Anderson (2001) publica uno de los estudios realizados por un grupo de científicos sociales. La investigación define desde el inicio el objeto del estudio y son «los valores y metas de vida de la población de la provincia de Yauyos» (p. 15). Se sabe que los valores no son directamente observables y son concepciones sobre lo deseable y que se ponen en evidencia en las prácticas. Proponen que es en este campo en el que se forman las identidades individuales y colectivas, donde las metas de vida se mueven en relación con los intereses (que 
pueden ser de bienestar físico y simbólico vinculados al reconocimiento) y las oportunidades, las que requieren de estrategias para conseguir metas concretas. En cierto modo el trabajo muestra la vida de los hombres y mujeres de Yauyos, «sus limitaciones, incertidumbres, empeños y oportunidades» (p. 18).

La situación de Yauyos no es monocultural. En su organización hay diferencias y, por lo tanto, también ópticas distintas de salida a sus problemas. Solo para mostrar un detalle, los autores consignan cuatro grandes estrategias para orientar y organizar sus vidas: la de permanecer en el lugar; la de permanencia en el lugar con miras a una expansión; la de emigración con retorno, y el último es la emigración definitiva. Aquí, sin embargo, es importante preguntarse si existen o no otras metas que no sean la del «progreso», que es equivalente a salir de su lugar de origen. El texto zigzaguea en las montañas de los pensamientos de los entrevistados, donde el progreso sigue siendo la idea más importante que orienta la vida de los yauyinos adultos, jóvenes y niños. De ser así, los valores son ideas formadas que determinan el camino ético que está en reelaboración y en profunda transformación. Por ello es necesario preguntarse: ¿desde dónde pensar la ética de los andinos? ¿Qué normatividades están presentes en las decisiones que realizan cualesquiera que fuera el destino que adopten los habitantes de los Andes? Es cierto, claro está, que la educación puede ser una poderosa emulsión para superar los campos baldíos producto de las colonizaciones aún pendientes, que es la propuesta con la que el estudio concluye su presentación. Es importante fijar que pensar sobre la ética es pensar las maneras de relaciones entre «seres humanos», cualesquiera que fuera la identidad de los «otros».

Sánchez (2003), de manera inusual, trata el tema de la ética pentecostal en el mundo popular. La orientación de vida oscilaría entre la apertura al mundo social y la orientación a la búsqueda del lucro individual. Según el autor, la ética pentecostal se estaría alejando de las fuentes fundamentales que explicarían el surgimiento del capitalismo. Por ello, las expresiones de la ética pentecostal en Latinoamérica se caracterizarían por favorecer la «prosperidad» y el bienestar económico y material como fines supremos a alcanzar y agradar a Dios. Las relaciones que establecen con los seguidores es la masividad antes que la comunitaria, empresarial antes que la pastoral. Se enfatiza el carácter de la «reciprocidad», vale decir que, a mayor aporte se entregue a la iglesia, mayores beneficios se recibirá de Dios, como lo plantea la iglesia «Pare de sufrir». Esto conlleva la fetichización de los productos para la protección de la salud y seguridad personal o familiar; en suma, las acciones que realizan los miembros de este tipo de iglesias pentecostales - como dice Sánchez- están orientadas por un «fuerte sentido del YO, del MÍ, de lo MÍO» (p. 399). Por otra parte, existe otra orientación entre los pentecostales, quienes desarrollan una ética más abierta al mundo basada en actitudes «más sociales y críticas». Este es el caso de los pentecostales de orientación metodista que han 
formado organizaciones de ayuda entre sus miembros con el propósito de superar la pobreza y la violencia familiar, entre otros. Son las iglesias de las Asambleas de Dios que hacen que las mujeres participen en las actividades litúrgicas como en las de liderazgo. Además, tratan de adaptarse a una sociedad cambiante.

En otro trabajo, Mujica (2004), recogiendo las preguntas de Marzal, intenta plasmar los primeros apuntes sobre la ética en el artículo «A Dios rogando y con el mazo dando». Las primeras preguntas están replanteadas a partir de algunas constataciones realizadas en el trabajo de campo entre los devotos del Señor de Cachuy (Yauyos). La ética de los devotos se caracteriza por la heteronomía, la pragmática y la inmanencia. Es heterónoma en tanto que la práctica social, económica y religiosa de los devotos está regida por una serie de obligaciones marcadas por el principio de reciprocidad, pues las actividades que se realizan solo tienen sentido en tanto pertenecen a una red muy grande de personas, las que están imbricadas por favores mutuos. Es pragmática en la medida en que las personas tienen que resolver problemas de inseguridad y de vulnerabilidad en los que están sujetos por razones de salud y de accidentes; vale decir que la riqueza se explica por la gracia divina, y la pobreza por la falta de corresponsabilidad de la persona con su santo patrono, de ahí que las personas están obligadas a realizar siempre actos de caridad para los necesitados. Finalmente, es inmanente en tanto que la satisfacción o la felicidad que se logra se hace ahora o nunca, de ahí que cada persona debe cuidarse y protegerse de muchas maneras haciendo uso de lo que sea necesario. Se puede resumir que la ética personal es heterónoma porque las normas son atribuidas a la divinidad, las relaciones de reciprocidad generan una serie de obligaciones y responsabilidad, y la realización se debe hacer en esta vida y no en la otra (cf. 2004: 231).

Para finalizar este ramillete poco usual, incluyo el trabajo de Theidon (2004). Aunque no es propiamente un trabajo sobre ética, su obra contiene uno de los materiales de la «postguerra» andina donde las moralidades y las éticas están a flor de piel y las heridas abiertas que se describen merecen ser atendidas con sensibilidad y sencillez. Entre prójimos constituye la descripción más vívida que la autora hace de su encuentro con el dolor humano y descubre en la palabra de cada víctima de las zonas ayacuchanas que la guerra interna había puesto en juego no solo la identidad de sus pobladores, sino su misma existencia. El estudio mira el sufrimiento y también la «resiliencia de la reconstrucción de la vida humana» ( $\mathrm{p}$. 21), sobre todo sabiendo que «el enemigo fue un 'enemigo íntimo' — un vecino, una nuera, un padrino o la comunidad de enfrente-. Entonces, parte de lo que hay que reconciliar no es solamente el sufrimiento experimentado, sino también el sufrimiento infligido. La tarea pendiente es 'rehumanizar' también al enemigo cuanto a uno mismo» (p. 22). 
El reto fundamental de este trabajo es, por tanto, humanizar las relaciones. Esto es posible revisando seriamente las concepciones antropológicas, así como los procedimientos de los que las personas se valen para reconstruir sus relaciones. Esto sería posible solo volviendo a ser considerados runakuna, lo que consistiría en «una conversión moral que conlleva a un 'cambio de corazón'. La noción de purificación figura prominentemente: la limpieza por medio de la confesión y el arrepentimiento son prácticas de largo plazo» (p. 204). A esto hay que añadir la «rehabilitación» y para eso es necesario — para simplificar una vez más el pensamiento de Theidon - una «economía política del perdón», donde el perdón es un proceso en el que «nadie puede forzar a una persona a perdonar a otra: es un estado, digamos, subjetivo» (p. 210). Por ello, el aporte de Theidon es definitivo y central para repensar la ética en la sociedad peruana, y para la antropología un reto que Marzal soñaba y que empezó ya a perfilarse, pero aún muy lentamente.

\section{LA AGONÍA DE LA ÉTICA «DURANTE AYACUCHO»}

Llegado a este punto es necesario preguntarse por los caminos por los que la antropología ha transitado, los hitos que ha ido dejando a las siguientes generaciones y evaluar si las señales y guías son útiles para futuras investigaciones. La presentación de algunos de los trabajos sobre la moralidad y la ética, desde la perspectiva antropológica, nos hace ver que el desarrollo de nuestra disciplina sobre el tema sigue siendo incipiente y desigual. La dificultad, por supuesto, probablemente proviene del tema mismo y de una metodología que no permite reconocer y recoger aquello que se quiere investigar y, sobre todo, de una realidad muy compleja de larga data y que durante las dos últimas décadas del siglo XX costó la vida de campesinos, quechuablantes y pobres.

No está de más recordar que el término ética, que etimológicamente significa habitación, manera de vivir en el mundo griego, pasa al latín como moral o costumbre, gracias a la traducción de Cicerón. En el pensamiento moderno la categoría ha sido materia de diversas precisiones e interpretaciones. Hoy se habla de moral y ética para designar, por ejemplo, la descripción y la reflexión que se hace de y sobre la conducta humana, respectivamente. Marzal, por ejemplo, entendía por ética el «conjunto de valores que funcionan como sistema normativo de los comportamientos individuales y colectivos» (2002: 173). Tomando en cuenta estos elementos, propuse definir la ética como «un conjunto de creencias o de ideas que genera determinadas actitudes y comportamiento hacia los otros» (Mujica 2004: 183). Aun así, sigo pensando que carecemos todavía de una definición precisa y funcional, pues la moral o la ética siguen siendo la manera de comportarse con los otros y la conciencia que se tiene de ese comportamiento. Las acciones que, 
conscientes o no, se realizan y afectan a los otros están determinadas por un conjunto de concepciones que se tiene del otro. La repetición de dichas acciones se convierten en un hábito y las acciones pasan a formar carácter cuando van fijando una determinada personalidad (cf. Aranguren 1995). Por supuesto, la ética, como cualquier producto humano, está también sujeta a cambios, modificaciones y reformulaciones con el correr del tiempo.

Sin embargo, en esta ocasión quiero levantar algunas observaciones generales en torno al difícil camino por el que la ética debe transitar y a los contextos sociales y culturales tan complejos como es el caso peruano y, sobre todo, «durante Ayacucho». Es común decir que la base de las relaciones está cambiando y en realidad no solo se trata de mestizajes o hibridices, sino también de elecciones que los individuos realizan para «vivir bien y mejor». En estos contextos, las maneras de vivir y las éticas, por supuesto, también se incrementan y se puede decir que no hay una sola forma de vivir la relación con la naturaleza y con el otro. La moral, en efecto, está directamente relacionada con la conducta humana, con la manera de relacionarse con las alteridades. Son estas conductas las que no son necesariamente «racionales» ni «irracionales», sino son solamente esas maneras de actuar y ejercer incluso poder y que obedecen a formas de concepción del otro y de su mundo. La ética, en todo caso, es aquella modalidad que la persona «conserva» como forma de comportamiento en tanto cuida no solo las formas, sino también la integridad del otro, la otredad definitiva, cualesquiera sean las maneras de expresarse. Dicho de otro modo, la ética es el comportamiento esperado y deseado que debiera ocurrir en el mundo social, y este tiene la finalidad de conservar, defender y promover la vida en sus diversas expresiones.

Para hacer una antropología de la ética en estos tiempos debe considerarse dos referencias metodológicas y al menos cuatro rutas por las cuales transitar para explorar la conducta de las personas en relación con otras. La primera referencia metodológica es la de considerar la conducta humana en su densidad y su meridiana sencillez; el acercamiento a esta realidad requiere de agudeza y —como decía Geertz- de una «densa descripción» de las moralidades (positivas o negativas) para tratar de entender qué está pasando en la vida de la gente. Es probable que para este punto sea imprescindible tomar en cuenta la recomendación de Agamben, quien dice que «entender la mente de un hombre común es infinitamente más arduo que comprender la mente de Spinoza o de Dante» (2002: 9). La segunda referencia se da en relación con la invitación a realizar un trabajo multidisciplinar: la reflexión. Este es el campo de la precisiones y de las evaluaciones que se hacen de las acciones de las personas y, sobre todo, de las valoraciones que están presente en la conducta humana y que orientan las acciones de la personas. Por ello, la ética es el terreno del debate y de la construcción de consensos comunes, 
un proceso de individuación y formación de conciencia colectiva, de un horizonte común y de la invitación a seguir construyendo las reglas «mínimas» para vivir como seres humanos.

Una vez consideradas las dos referencias quiero terminar mencionando las cuatro rutas posibles para el estudio de las moralidades y la ética, desde la perspectiva antropológica. Ello, tomando en cuenta que la vida humana es multidimensional y que, arbitrariamente, aquí hago hincapié a cuatro dimensiones donde habría que considerar la ética en relación con la vida cotidiana, la religiosidad, la economía y política.

En primer lugar, el mundo de la vida cotidiana está surtido de formas sutiles y habituales de tratamiento de desprecio y de discriminaciones que pasan muchas veces inadvertidas. Las formas de exclusión por razones étnicas, raciales, de género o de clase se reproducen larvada y «descaradamente»-como decía alguien - en las relaciones cotidianas. ¿Qué hace que unos puedan discriminar a otros y viceversa? Para esto se requiere de una aguda y penetrante observación, pues se trata de deconstruir las maneras de excluir a los otros desde algún punto de referencia considerado como el axis del mundo. En la conducta y la acción de uno está implícito el concepto del otro y, por ello, para comprender mejor la ética se debe estudiar las concepciones de ser humano. De la Cadena, por ejemplo, por ello, propone estudiar el racismo como «el conjunto de prácticas discriminatorias que se derivan de una creencia en la indiscutible superioridad moral e intelectual de un grupo de peruanos sobre el resto» (2004: 21); ello, en referencia a los «indígenas mestizos», donde ella descubre que la cuestión racial atraviesa capilarmente todos los segmentos e instancias sociales y que se ha convertido en algo natural, culturalmente. Esta realidad (no un asunto del pasado) está presente, como lo recuerda Pease al evaluar el Congreso; allí dice: «Aquí cada presidente y cada ministro se siente un salvador, tienen experiencias que lo hacen sentirse "por encima" y con poder» (2005: 15).

En segundo lugar, el mundo de las religiosidades está nutrido de normas que orientan y dan sentido a la vida de los creyentes. En este campo, Manuel Marzal encuentra el medio natural más importante para hacer trabajos sobre ética. De hecho, el campo de las religiosidades es donde se forman las maneras de definirse como grupo. En él puede llegar a formarse, incluso, una suerte de «identidades asesinas», en la medida en que elijan un elemento como el más importante, sino como el absoluto, desde donde se cuestiona y se discrimina a los otros, incluso en nombre de un dios. La tentación de los «fundamentalismos» está presente en la vida peruana, aunque no tenga una identidad religiosa propiamente dicha. Sin embargo, es también el terreno de la religiosidad donde las personas establecen formas de solidaridad y cooperación y hacen de su fe una forma de compromiso 
por el cambio y la justicia, aquí y ahora. Definitivamente, la ética religiosa modela de muchas maneras el comportamiento de las personas que requieren ser descritas $\mathrm{y}$ analizadas con seriedad.

En tercer lugar, la ética requiere ser considerada también en el campo de los desempeños de las personas y de las instituciones, las cuales tienen por finalidad mitigar el hambre y que las personas tengan una vida de calidad y plena. Un problema central en este campo son las inequidades y las injusticias en la redistribución de las riquezas de todas las especies. ¿Cómo y con qué criterios se deciden las redistribuciones de los bienes producidos por la sociedad? La distribución implica concepciones de la tarea humana y de sus relaciones en los espacios privados y públicos. Adela Cortina (1996) ha señalado que las empresas, por ejemplo, deben considerar — y en serio- la ética para una producción y distribución. Sin embargo, debemos observar con detenimiento lo que significa hoy la explotación del hombre por el hombre, por ejemplo, en el mundo de las microempresas; es probable que la modalidad cruel y cruda de la explotación haya sido cambiada por una «estetizada» donde, por ejemplo, los derechos laborales simplemente no existen. Del mismo modo, en el campo público, el tratamiento que se hace de los recursos públicos no escapan a formas de solidaridad donde la corrupción — como dice Jaris Mujica - constituye «un modo particular y complejo de relacionarse [que] se convierte así, en un fenómeno generador de prácticas y en punto de referencia de un modo diferente de entender, plantear y pensar la política, el poder y la autoridad» (cf. Ugarteche 2005: 135), o como recuerda Deborah Poole, que la corrupción son «las formas de descomposición política y moral que se derivan de las transgresiones (reales o imaginadas) de la línea divisoria que separa la vida pública y privada» (cf. Ugarteche 2005: 61).

Finalmente, la ética en el campo político atraviesa su forma más dramática cuando vemos en el horizonte más cercano maneras de actuar impunemente y que son aceptadas sin ambages por el sentido común. Los hechos de violencia vividos por cerca de dos décadas nos hacen pensar que la ética «durante Ayacucho» está a flor de piel. El mal, melifluamente, se instala en las mentalidades y las prácticas de muchos sectores sociales y es aceptado como «normal» o como parte de la «naturaleza humana». Gonzalo Portocarrero (2004) ha iniciado una importante reflexión de las formas de hacer el mal en la cultura peruana. Lo concibe «como un abandonarse al goce que puede generar la destrucción de la vida, como una forma excitante de escapar al vacío primordial de la existencia» (Portocarrero 2004: 9). Sin embargo, queda pendiente el estudio de la ética a partir de lo que la Comisión de la Verdad y Reconciliación ha hecho y dicho en su Informe Final. Este es un punto de llegada y también de partida para responder preguntas de importancia para la viabilidad del país y la construcción de un sistema plural y tolerante de las relaciones. Para ello es impostergable el estudio de las múltiples 
formas de impunidades por parte de los actores de las violaciones sistemáticas de los Derechos Humanos, como Sendero Luminoso, las fuerzas del orden y los grupos civiles armados. Pero también es importante revisar las responsabilidades e «impunidades» de los partidos políticos, las empresas, de los intelectuales y de los grupos de la sociedad civil.

Para concluir, diremos que la agonía de la ética está en manos de las personas y las instituciones que quieren comprometerse en cambiar las condiciones de vida no deseables. Agon es el término griego que se puede traducir por «lucha». Por ello, la agonía de la ética es la lucha por la vida mejor, que el mundo de las «moralidades» sea también «ético». Cuando Manuel Marzal dejó este mundo para encontrarse con lo «Realmente Real», el reloj de la historia ha seguido marcando el ritmo de la vida y sus campanadas siguen alertando aquello que no se debe dejar de investigar y reflexionar: las formas en que se producen las desigualdades, los fundamentalismos sectarios, las solidaridades corruptas y las impunidades en los diversos campos de la vida humana; pero también cómo se construyen los reconocimientos de lo diverso, cómo se hacen más tolerantes las personas, cómo se hacen más diáfanos los servicios públicos y, finalmente, cómo se hacen más humanos los que detentan el poder.

\section{BIBLIOGRAFÍA}

a) Bibliografía básica de Manuel Marzal

Marzal, Manuel

1977 Estudios sobre religión campesina. Lima: PUCP.

1983 La transformación religiosa peruana. Lima: PUCP.

$1985 \quad$ El sincretismo iberoamericano. Lima: PUCP.

1988 Los caminos religiosos de los inmigrantes en la gran Lima. Lima: PUCP.

2002 Tierra encantada. Tratado de antropología religiosa de América Latina. Lima-Madrid: PUCP-Trotta.

Marzal, Manuel, Xavier Albó y Eugenio MaURer

1991 El rostro indio de Dios. Lima: PUCP.

Marzal, Manuel, Catalina Romero y José SÁnchez

2004 Para entender la religión en el Perú 2003. Lima: PUCP. 


\section{b) Bibliografia complementaria}

Adams, Norma y Néstor VAldivia

1991 Los otros empresarios. Ética de migrantes y formación de empresas en Lima. Lima: Instituto de Estudios Peruanos.

Agamben, Giorgio

2002 Lo que queda de Auschwitz. El archivo y el testigo. Homo Sacer III. Valencia: Pre-Textos.

ANDERSON, Jeanine (coordinadora)

2001 Yauyos. Estudio sobre valores y metas de vida. Lima: Ministerio de Educación.

Aranguren, José Luis

1995 Ética. Madrid: Alianza Universidad.

CAdena, Marisol de la

$2004 \quad$ Indígenas mestizos. Raza y cultura en el Cusco. Lima: IEP.

Castro, Augusto

1994 El Perú, un proyecto moderno: una aproximación al pensamiento peruano. Lima: IRA-CEP.

Cortina, Adela

1996 Ética de la empresa. Madrid: Trotta.

GonzÁlez, José Luis

1987 La religión popular en el Perú. Informe diagnóstico. Cusco: IPA.

Howell, Signe (editor)

1997 The Ethnography of Moralities. London-New York: Routledge.

Escalante, Carmen y Ricardo Valderrama

1992 Nosotros los humanos. Nuqanchik Runakuna. Testimonios de los quechuas del siglo XX. Cusco: CERA Bartolomé de Las Casas.

ESTERMANN, Josef

1998 Filosofía andina. Estudio intercultural de la sabiduría autóctona andina. Quito: Abya-Yala.

Figueroa, Adolfo, Teófilo Altamirano y Denis Sulmont

1996 Exclusión social y desigualdad en el Perú. Lima: OIT.

Flores Lezama, Carlos

2004 Diario de vida y muerte. Memorias para recuperar humanidad. Ayacucho 1988-1991. Cusco: CADEP-CBC. 
LIPOVETSKI, Gilles

1998 El crepúsculo del deber. La ética indolora de los nuevos tiempos democráticos. Barcelona: Anagrama.

MaLinowsKi, Bronislaw

1971 La vida sexual de los salvajes del noreste de la Melanesia. Madrid: Ediciones Morata.

MuJicA, Luis

1998 Los valores en jóvenes estudiantes universitarios. El caso de los cachimbos 1997-1 y 1997-2. Lima: CISEPA-PUCP.

2004 «A Dios rogando y con el mazo dando. Aproximaciones a la ética de algunos comerciantes devotos». En Manuel Marzal, Catalina Romero y José Sánchez. Para entender la religión en el Perú 2003. Lima: PUCP, pp. 184-237.

NeYra, Eloy

1993

«Cuando no trabajo me da sueño: Raíz andina de la ética del trabajo». En Los nuevos limeños. Sueños, fervores y caminos en el mundo popular. Lima: SUR-TAFOS, pp. 45-53.

Pease, Henry

2005 «Para un balance del Congreso de la República 2001-2006». Coyuntura. $\mathrm{N}^{\circ} 4$, pp. 12-15.

PEÑA, Antonio

1998 Justicia comunal en los Andes del Perú. El caso de Calahuyo. Lima: PUCP.

Portocarrero, Gonzalo

2004 Rostros criollos del mal. Cultura y transgresión en la sociedad peruana. Lima: Red para el Desarrollo de las Ciencias Sociales en el Perú.

SALAS, Ricardo

2003 Ética intercultural. (Re)Lecturas del pensamiento latinoamericano. Santiago: Ediciones UCSH.

SÁNCHEZ, José

2003 «La ética pentecostal: entre lo tradicional y lo moderno en las sociedades latinoamericanas». En Actas del IX Congreso de ALER: Religión y etnicidad. La religión en el Nuevo milenio una mirada desde los Andes. Tomo III. Lima: PUCP, pp. 393-402.

Santos Granero, Fernando

1994 El poder del amor. Poder, conocimiento y moralidad entre los Amuesha de la selva central del Perú. Quito: Abya Yala - Centro Amazónico de Antropología y Aplicación Práctica (CAAAP). 
Soто, Ricardo

1998 La ética del progreso basada en la cultura. Huancayo: Centro Cultural José María Arguedas.

THEIDON, Kimberly

2004 Entre prójimos. El conflicto armado interno y la política de la reconciliación en el Perú. Lima: IEP.

UgARTEChe, Óscar (compilador)

2005 Vicios públicos. Poder y corrupción. Lima: SUR-FCE. 